\title{
A REE completa sua primeira década!
}

\section{Marcelo Medeiros', Denize Bouttelet Munaril}

' Enfermeiro. Doutor em Enfermagem. Editor da Revista Eletrônica de Enfermagem (REE). Professor Associado da Faculdade de Enfermagem da Universidade Federal de Goiás. Goiânia/GO. E-mail: marcelo@fen.ufg.br.

"Enfermeira. Doutora em Enfermagem. Editora Executiva da REE. Professora Titular da Faculdade de Enfermagem da Universidade Federal de Goiás. Goiânia/GO. E-mail: denize@fen.ufg.br.

A Revista Eletrônica de Enfermagem (REE), primeiro periódico eletrônico da área de Enfermagem publicado no Brasil, criada em 1999, completará dez anos de existência em outubro deste ano. Na sua primeira década de existência passou por diversas fases no seu processo de editoração, mudanças surgiram acompanhando avanços tecnológicos, porém sempre mantendo seu caráter de circulação exclusiva pela internet, acesso livre e gratuito.

No processo de editoração da REE ao longo desta década, os três volumes iniciais foram preparados por meio de editores de texto e de páginas web e disponibilizados na internet apenas no formato HTML (Hypertext Markup Language). A partir do quarto volume os textos também foram disponibilizados no formato PDF (Portable Document Format), que surgiu como padrão de impressão para documentos em formato eletrônico e obtido por meio do software apropriado. A comunicação entre equipe editorial, colaboradores e avaliadores ocorria por mensagens eletrônicas, cópias em disquetes e impressas enviadas via postal, sendo os dois últimos formatos abolidos desde 2004.

Para inserção da REE em bases de dados de literatura científica reconhecidas e que permitissem melhorar sua qualificação no Qualis-Capes, a política de editoração passou por mudanças significativas desde 2006. Na avaliação dos periódicos, naquele ano, alcançou o Qualis "Internacional C" e sua inclusão no Portal de Revistas na BVS/Enfermagem, adotando para este portal o modelo de diagramação SciELO (Scientific Electronic Library Online).

Esta política se concretizou em 2007, quando regras de preparo e submissão de artigos passaram a ser baseadas nas orientações do Comitê Internacional de Editores de Revistas Médicas (estilo Vancouver). Na editoração eletrônica, acompanhando a evolução de softwares, novos sistemas de editoração em HTML, PDF e imagens foram adotados.

Ao iniciar o ano de 2009 novos desafios se desenham para a equipe da revista, que tem se dedicado de maneira incansável na corrida em busca do melhor desempenho do periódico. Assim, a REE vem conquistando confiabilidade e credibilidade como veículo de divulgação do conhecimento nas áreas de Saúde e Enfermagem. Ao completar a primeira década, observa-se aumento crescente de demanda para publicação procedente de colaboradores de diversos estados do Brasil, Américas, Europa, Oriente Médio que, em maioria, vinculam-se às instituições de ensino superior e/ou Programas de Pós-Graduação Lato e Stricto Sensu.

Atualmente, indexada em bases como DOAJ, BDENF, LILACS, CINAHL, CUIDEN, PERIÓDICA, entre outras, a REE tem cumprido sua missão na socialização do conhecimento, buscando excelência em atender normas e padrões internacionais, mantendo-se como Open Access J ournal, tal como fora pensada em 1999.

Para finalizar, destacamos e agradecemos à colaboração e dedicação de todos os autores, dos membros do Conselho Editorial e ad-hoc, da equipe da REE, e também aos técnicos e monitores, pois sabemos que cada conquista e avanço é fruto do esforço coletivo de todos os envolvidos no processo de submissão, avaliação e preparo para disponibilizar a Revista na internet. Sobretudo, agradecemos ao nosso leitor, que torna válida a nossa intenção de buscar cada vez mais a excelência neste trabalho. 